\title{
ENHANCING PARTICIPATION IN INTERDISCIPLINARY STUDENT TEAMS THROUGH THE USE OF TANGIBLE REPRESENTATIONS
}

\author{
Ann Kristin FORSHAUG \\ Norwegian University of Science and Technology (NTNU), Faculty of Architecture and \\ Design, Department of Design
}

\begin{abstract}
Designers are to an increasingly extent working as facilitators and members of co-creative interdisciplinary teams. Interdisciplinary collaboration is needed when working with complex problems, and more knowledge on how to best facilitate co-creative design processes are needed. This study is looking into participation in decision making, and how the use of tangible representations may influence the team members opportunities to participate.

This paper is exploring the experiences of using an adapted affinity mapping exercise for facilitating decision-making in interdisciplinary student teams. They are all working on developing new concepts for future health care services through methods from service design and design thinking. After using an adapted affinity mapping exercise, the teams are interviewed about their general experiences of the design process, and their understanding of how the use of tangible representations are influencing their participation and decision-making process.

The student teams describe the affinity mapping exercise as an engaging and motivating work mode, and they all reach to a final decision they experience as shared. The Post-it's are described as a work tool which is easily accessible, and which may lower the threshold for participation. Working with tangible representations may help the teams handle a wider diversity of the content, getting a shared overview and making more thorough decisions.
\end{abstract}

Keywords: Interdisciplinary teams, design facilitation, design methods, affinity mapping, participation, effective teams

\section{INTRODUCTION}

Interdisciplinary participation is needed when working with complex and wicked problems, and cocreation with stakeholders is key to several design disciplines, such as service design and design thinking. Several others have been interested in how different stakeholders may be included and involved in the development of new solutions. Participation is key to make solutions that are implementable, and to base new solutions on knowledge from the various disciplines that are needed. The aim of this study is to explore how the use of an affinity mapping exercise[1] influences the decision-making process in interdisciplinary co-creative teams. The teams are working on creating new concepts for future health care services. The focus is especially on participation, and how the use of Post-it's, and other external and tangible representations influence team-members participation. The motivation is to gain more knowledge on how co-creative processes should be facilitated, and how we as design facilitators, workshop leaders and participators in design processes may help enhance the interdisciplinary participation.

Based on reflections done in co-operation with the student teams, the topic is discussed and reflected on. The findings are further discussed on the basis of literature on effective teams, decision making and participation. 


\section{BACKGROUND}

Co-creation and stakeholder involvement in the process is considered as a key factor in many design disciplines, e.g. service design [2]. Sanders and Stappers [3] sees co-creativity as "any act of collective creativity", and co-design as the act of designers and non-designers working together as partners throughout the design process. They are discussing the differences in seeing the user as a subject or seeing the user as a partner. When "non-designers" are active partners in the design process it calls for new methods and knowledge on process facilitation. One essential element of processes are decisions. Decisions are made in every step in the design process but are more visible in some parts of the process than others.

An understanding of different ways of decision-making and the effect on group processes could be found in the work of organisational psychologist Schein[4]. He describes six different methods of decisionmaking: unanimity, consensus, majority rule, minority rule, authority rule, and lack of group-response. Unanimity is where everyone truly agrees on the course of action to be taken. Some key decisions may require this, but for most decisions consensus is enough. To seek consensus is often time-consuming, but in the long term, one of the most effective decision-making processes. Schein [4, p73] defines this as "a state of affairs where communications have been sufficiently open, and the group climate sufficiently supportive, to make everyone in the group feel that he has had his fair chance to influence the decision". Voting could be to poll everyone's opinion after a period of discussions or having more formal routines where people give points or votes. Despite being effective in finding a decision, these decisions may not be well-implemented and could induce coalitions and feelings of being misunderstood and resentfulness. Decisions by minority are when a minority of the group more or less consciously are railroading decisions. The idea of "silence means consent" and the social cost of challenging these decisions may lead to a lack of opposition from group members. Groups may accept railroading and minority decisions at some occasions, because of lack of time and that decisions had to be made. Authority rule is when someone in authority make decisions. This is highly efficient, but effectiveness depends on the authority person, and his skills on listening and gaining the right basis of the decisions. If the group misunderstand the authority decision, or don't agree this may have consequences for the implementation of the agreements. Lack of group response is the most common and least visible of group decision-making methods. This happens when suggestions don't get a response from the rest of the team and are thereby bypassed. Schein emphasises that no single decision-making method is sufficient or effective for all teams, but teams should choose decision-making rules that fits to the appropriate time available, the past history of the group, the project task, and which climate the group want to establish.

Affinity mapping/affinity diagramming is a process technique used both in analysis and synthesis to externalise insights and meaningfully cluster them in themes [1]. The method is described in several variations and adapted to the project, but are usually an inductive exercise, done in collaboration with several team-members, involving Post-it's and large sheets of paper or whiteboards. Some of the proposed benefits are shared awareness, cognitive offloading and understanding, organising and [5].

\section{METHOD}

\subsection{About the course and the affinity mapping exercise}

Experts in Teamwork (EiT) is a mandatory course for all master level students on NTNU[6] focusing on development of interdisciplinary teamwork skills. The students involved in this study, take the course-module "Design of future health care services" where they are developing new concepts for the future health care services, through methods from service design and design thinking. Throughout the semester the teams are meeting fifteen times, and a minimum 120 hours. The course is using an experience-based learning form, and the students are actively reflecting on their team experiences throughout the semester. The teams are observed by teaching assistants and occasionally get feedback which may trigger reflections and actions. The teams are interdisciplinary with students from e.g. economy, architecture, design, engineering science, psychology and mathematics. Most of the students are familiar to neither the health care context nor the use of design methods.

This paper is exploring one of the teams' first task; to collaboratively explore and decide on a design challenge. Based on the overall intentions of the course EiT, the chosen design challenge had to fulfil three criteria:

- The chosen topic should address a social issue in health 
- It should be able for all team members to commit and engage to the chosen topic

- The topic should make it possible for all team members to use their individual competences

The students had prepared by looking at current health related topics in media and politics. They were asked to bring at least one physical printout from a topic that engaged them. This topic was shared with the rest of the team, and they were together exploring the different topics and deciding on a design challenge. As a tool for the decision-making process, an adapted affinity mapping exercise was suggested. As one of the main goals for this course is to let the teams experiment and reflect on how different structures are influencing team behaviour, few strict guidelines on their decision-making process were given. The teams were encouraged to first write some notes on an individual basis, and to find a sort of structured go-through of the notes so that all team members got to share their perspective. They were also encouraged to ask following up questions and provide feedback to other team-members.

\subsection{Data gathering and analysis}

Group interviews were conducted to explore and reflect around the teams' experiences with the affinity mapping exercise used as a tool to facilitate their decision-making when defining and deciding on a design challenge. In total 4 group interviews were done, with a total of 19 students. The interviews lasted from 30-60 minutes. Written field notes have been used as a primary source in the analysis.

The interview started by asking the groups to describe their decision process, and how they interpreted and used the suggested affinity mapping exercise. They were then asked to reflect around participation, to get an understanding in what they put into the term "participation" as well as their preunderstanding of participation. Again, they were asked to reflect around how they saw that this particular exercise, and working with tangible representations, influenced their participation.

The interview data were analysed by the author with the aim of identifying enablers and barriers of participation in interdisciplinary teams working with tangible representations. The analysis was mainly content driven. The main results are presented in the next section.

\subsection{Results}

All teams seem to believe that working with tangible representation makes them more engaged and motivated over time. The teams were all experimenting with different decision-making tactics. Ranging from "it just happened that way" to structured voting processes and consensus. It is a part of the course to reflect on how the teams are making decisions, thereby the teams were changing and adapting their decision-making process as they go.

With Post-it's your participation becomes visible and evident. As one of the students framed it: "Your individual production frequency becomes quite clear". Most of the students seemed to see this as a positive pressure, and that it encouraged participation. One of the team saw that making individual notes "forced" everyone to think and to be more active. When people pull out of a team whilst just having a verbal discussion it is much more up to interpretation why this is happening, one person pointed out. "Maybe the person is shy, or not mentally present, or just doesn't want to participate. But with Post-it's I think it makes it so explicit, you can't hide. It becomes so clear if you haven't produced any notes." The student teams are describing participation as being active, engaged, motivated, and contributing to the team work. They are all highlighting that participation could come in many shapes and forms and emphasise that it is not directly correlated to talking time. Asking questions, showing interest, and facilitating the conversation is also seen as participation. However, what you bring to the table should be of value for the project. It seems to be a strong norm amongst the students to "be a participator". As one said it: "Everyone has been in that group where one person is not contributing. You really don't want to be that person".

One person raised the question about the norm on "participating" all the time. He felt that this exercise demands a lot of energy, and sometimes he felt it was necessary to pull out and get a more metaperspective of the group. He thought it was more important to participate more actively when he had something new to add. His team agreed that variation in work modes is essential, and one of his teammembers added: "Had we done this for eight hours a day I think we would have killed each other".

The students felt that the tangible representations could lower the threshold for participation. It made room for contributing in other ways than by just talking. "Especially when the group is discussing technical matters, I don't feel that I have anything to add. But with the Post-it's I could help write things down and organise the notes". Several students had former experiences of team work where they were hindered to participate due to the specific working tool (computer programs) and was emphasising that 
Post-it's were a media that could be used by everyone. The students were also mentioning how a Postit could be a tool to help you join in on the conversation. One of them referred to it as a "talking stick". He felt that it was easier to speak out loud when he had a Post-it to present. He liked that he could formulate what he was going to say and write some cues on the Post-it. This especially worked well when he could have individual working time in between the shared sessions. Another student pointed out that he believed the tangibility of the notes made it easier for him to organise his thoughts. "The Post-it is something physical which I can move around. I believe that helps my brain sorting things out". Several others agreed that the physicality is nice. "It is so nice that it is so concrete. It feels more constructive and things get more attention when it has a physical note".

The students were also reflecting on how the media of the conversation changed their feelings about their project. Working with less text than they were used to was seen as engaging. All the teams referred to "laptop work" as their regular way of working. They said laptops made more distractions and saw it as a physical blockage of communication. Without the laptops they could be more attentive to each other and be more present. The media also changed the feelings of the content and how shape able it would be later in the process. Writing long sentences in GoogleDocs were looked at as both time-consuming as well as leading to an impression that people had put a lot of effort into the work. Thereby making it harder to change later on.

All teams saw affinity mapping as an approach that was enabling the team to make more thorough decisions. Partly it seemed as a result of the type of communication patterns the affinity exercise encouraged. "I like how this made us think about everything" one said. Another emphasised that "it was a nice exercise to get a feeling on what the other people saw as interesting". It seemed like the exercise encouraged a culture that promoted a wider diversity of what was put on the table. When asked in general about what they saw as hindering participation, the teams were describing issues such as lack of selfesteem, feeling inferior to others in the team or the feeling that you didn't have anything of value to bring to the table. The tangible representations also made it more evident if there were elements that the team was avoiding discussing. "Seeing it there forces us to discuss it", one participant said.

Partly the thorough foundation for the decision-making seemed to be because of what they saw as the affinity mapping exercise creating a "visual and holistic overview". "It makes it possible to see the bigger picture and being concrete at the same time", one person said. It also helped structuring the chaos and connecting the dots. "It is so much easier to see connections when you have it up there on the wall than when things are just written in a document", one said. The visual overview made it possible to see new elements. Things they hadn't seen before. It made them focus on trends and correlation between topics. One of the teams pointed out that seeing connections made it easier to build on each other's ideas, and thereby making it easier to find shared topics that people could agree on. The overview of topics also made it easier to merge the topics of two notes, and to treat content more like a continuous spectacle, and not so much either-or answers as in documents. Two different things can have something in common, and together turn out to be a part of the same concept. "We feel that we have made this decision together now. We know the reasons why we ended up here, and that there is a lot of meaning behind it". Sometimes this thoroughness led to using what they saw as an unnecessary amount of time on topics they felt wasn't relevant. This was done because they wanted to systematically work through everything. However, the teams seemed to agree that the end result was of better quality when they worked systematically and thorough.

To make the decision-making process more effective, one team was experimenting with time pressure, and was reflecting on how this affected their participation. Part of the exercise they decided to work on a strict time limit. They all agreed that time pressure influenced the result in some way or another. Some team members felt that time pressure put a "block" in their head, whilst other felt it made them come up with more and better thoughts and ideas. One of the team-members felt that he got the impression that decisions made in the time pressure-sessions were less likely to hold, and that they often had to go back on them later on. In the end this team ended up in distinguishing between sessions where the aim was to produce a lot of ideas and loose ends, and sessions where they needed to get to necessary consensus and mutual agreements.

The Post-it's became $a$ shared and visible memory of what the team had been discussing. They saw that writing things down was a good way to remember things that were discussed and mentioned earlier on. One aspect the teams saw as positive, was that it made it less likely to move on with the topics that were discussed most loudly, or latest in the conversations. Several of the teams thought this could help make the conversation less dependent on oral skills and reduce the risk of a team that were dominated by those 
who were "good with words" and "good at getting their opinion across". However, the teams differed in their opinions whether this visual way of working also made the decision-making biased in new ways. Would more notes on a topic make it more likely to be chosen? Or will equally size Post-it's make all topics equally important?

\section{Discussions}

The aim of this study was to explore how the use of an affinity mapping exercise influences the decisionmaking process in interdisciplinary co-creative teams, with the main focus on how the use of Post-it's, and other external and tangible representations influence team-members participation.

As I see it one of the most interesting findings is how the teams seem to feel that they were working more like a team, that the final choice was jointly explored and that they all feel engaged in their final result. There are reasons to believe that the exercise stimulate to what Schein describes as consensus: "a state of affairs where communications have been sufficiently open, and the group climate sufficiently supportive, to make everyone in the group feel that he has had his fair chance to influence the decision." The affinity mapping exercise is seen as time-consuming and might not be experienced as an effective decision-making process under all circumstances. As pointed out by one of the teams, sometimes it makes too much room for ambiguity, off-tracking and thorough discussions. Variation of work methods are suggested. As suggested by Schein[4] several different decision-making strategies may work as long as you carefully chose one for the task at hand. In co-creation processes, where participation is considered key for developing good and implementable solutions [7] there is a need to pay particular attention to how decisions are made and that participants are actually participating actively in the decisions.

Based on reflections from the students there are reasons to believe that the affinity mapping exercise may lower the threshold for the participation. This is mainly not due to the Post-it's per se, but rather ways of structuring the process such as individual thinking time, the expectations that everyone should contribute with content (in the form of Post-it's) as well as the expectation that you don't have to sort or self-sensor content before it is put on the table in this mode of working.

The students are also highlighting several consequences of different ways of structuring the process. Such as the team experimenting with time pressure and saw how this might trigger different individual reactions and gives different results on the decision-process. These structures are typically set by a design facilitator.

\section{CONCLUDING REMARKS}

This study has explored how five different interdisciplinary student teams experiences an affinity mapping exercise as a tool for a decision making-process, and how they see working with tangible representations influence their participation and decisions being made. Some conclusions and reflections are drawn, which may be of interest of designers facilitating co-creative interdisciplinary teams and cocreative sessions such as workshops.

The student teams describe the affinity mapping exercise as an engaging and motivating work mode, and they all reach to a final decision they experience as a shared decision. The Post-it's are described as a work tool which is easily accessible, and which may lower the threshold for participation. Working with tangible representations may help the teams handle a wider diversity of the content, getting a shared overview and making more thorough decisions.

The study is limited to a small number of participants and the knowledge is attained with group interviews. Students has been the target group of the study; other answers will probably be found in nonstudent groups. As one of the students said it: "I guess it is harder for people that has formed their opinions over five years or a decade to change their mind and make new solutions than it is for us". Further studies on more long-term and ongoing projects are suggested.

\section{REFERENCES}

[1] Hanington B. and Martin B. Universal methods of design: 100 ways to research complex problems, develop innovative ideas, and design effective solutions: Rockport Publishers; 2012.

[2] Stickdorn M. and Schneider J. This is Service Design Thinking: Basics, Tools, Cases: BIS Publ.; 2012.

[3] Sanders E.B-N. and Stappers P.J. Co-creation and the new landscapes of design. Co-design. 2008;4(1):5-18. 
[4] Schein E.H. Process consultation: Its role in organisation development. 1969.

[5] Judge T.K., Pyla P.S., McCrickard D.S., Harrison S. and Hartson H.R. Studying group decision making in affinity diagramming. 2008.

[6] [Webpage]. [Available from: https://www.ntnu.edu/eit.

[7] Blomkvist J., Holmlid S. and Segelström F. This is Service Design Research: Yesterday, today and tomorrow. This is Service Design Thinking: Basics-Tools-Cases. 2010. 